\title{
Effect of different loading conditions on running mechanics at different velocities
}

\author{
GERMÁN CARRETERO-NAVARRO ${ }^{1}$, GONZALO MÁRQUEZ ํํㄹ, \\ DOMÉNICO CHERUBINI ${ }^{1}$, \& WOLFGANG TAUBE ${ }^{2}$
}

\author{
${ }^{1}$ Departamento de Ciencias de la Actividad Física y del Deporte, Facultad de Ciencias de la Actividad Física y del Deporte - \\ UCAM, Universidad Católica San Antonio de Murcia, Murcia, España $\mathcal{E}^{2}$ Department of Medicine, Movement and Sports \\ Science, University of Fribourg, Fribourg, Switzerland
}

\begin{abstract}
Weighted vests are widely used to improve running economy and performance. However, it is not well-studied how running mechanics are adapted to counteract the higher peak vertical ground reaction forces (Fpeak) while running with such a device. Therefore, the present study aimed to investigate the effects of different loading conditions on running mechanics at different velocities. Thirteen subjects participated in two separate sessions one week apart. In the first session, maximal aerobic speed (MAS) was determined through a maximal incremental running test while in the second session, they were instructed to run during one minute under different loading $(0 \%,+10 \%$ and $+20 \%$ of body mass $[\mathrm{BM}])$ and velocity $(60 \%, 80 \%$ and $100 \%$ of MAS) conditions in a random order. Spatiotemporal data were recorded and then running mechanics modelled using the spring-mass model. The main results indicated that vertical and leg stiffness (Kvert and Kleg, respectively) were increased $(P<.001)$ as velocity increased but remained unaltered $(P>.05)$ when load was changed. At the same time, alterations of the running kinematics were observed such as longer contact times, reduced flight times, stride frequencies and step lengths, as well as an increase of the centre of mass dynamics. Based on these results it is assumed that runners maintain a certain stiffness level for each velocity despite different loading conditions. As a consequence, Fpeak increases and this probably causes spatiotemporal adjustments in the movement kinematics.
\end{abstract}

Keywords: Spring-mass model, running, weighted vest, stiffness

\section{Highlights}

- Lower extremity stiffness influences running economy and performance playing an important role in performance.

- The interaction of different loading and velocity conditions on spring-mass behaviour has not been investigated.

- Alterations of the running kinematics were observed when wearing weighted vests loaded with $10-20 \%$ of the BM during running at different submaximal velocities.

- Runners maintain a certain stiffness level for each velocity despite different loading conditions.

\section{Introduction}

During running activities the kinetic and kinematic parameters, together with metabolic factors (peak oxygen uptake $\left.\left[\mathrm{VO}_{2} \mathrm{max}\right]\right)$ and their interactions (running economy), play an important role in running performance (Abe et al., 2011; Saunders, Pyne, Telford, \& Hawley, 2004; Williams \& Cavanagh, 1987). In this regard, the spring-mass model has been widely used to describe and predict running mechanics (Blickhan, 1989; McMahon \&
Cheng, 1990). This model simulates the mechanical behaviour of the lower limb as a simple spring (leg spring) and a mass equivalent to the body weight (Blickhan, 1989). Moreover, it is commonly accepted that the most relevant parameters of this model are vertical and leg stiffness ( $\mathrm{K}_{\mathrm{vert}}$ and $\mathrm{K}_{\mathrm{leg}}$, respectively). $\mathrm{K}_{\mathrm{vert}}$ is used to describe the vertical motion of the centre of mass (CoM) during contact (Farley \& González, 1996; McMahon \& Cheng, 1990) and is defined as the ratio of the peak vertical ground

Correspondence: Gonzalo Márquez, Departamento de Ciencias de la Actividad Física y del Deporte, Facultad de Ciencias de la Actividad Física y del Deporte - UCAM, Universidad Católica San Antonio de Murcia, Campus de los Jerónimos s/n. 30107-Guadalupe, Murcia, Spain. E-mail: gmarquez@ucam.edu 
reaction force $\left(\mathrm{F}_{\text {peak }}\right)$ to the vertical displacement of the $\operatorname{CoM}(\Delta y)$ as the latter reaches its lowest point in the middle of the stance phase (Farley \& González, 1996). In contrast, $K_{\text {leg }}$ is defined as the ratio of the $\mathrm{F}_{\text {peak }}$ in the spring to the maximal leg compression $(\Delta \mathrm{L})$ assessed in the middle of the stance phase

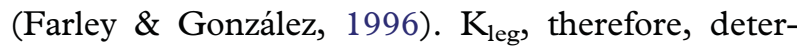
mines the interaction between the environment and the human body (Ferris, Louie, \& Farley, 1998) playing a decisive role in running mechanics (Blickhan, 1989; Farley \& González, 1996; Farley, Blickhan, Saito, \& Taylor, 1991; McMahon \& Cheng, 1990). Additionally, many other factors such as step frequency (Farley \& González, 1996), step length (Barnes, McGuigan, \& Kilding, 2014), velocity (Brughelli \& Cronin, 2008; Kuitunen, Komi, \& Kyröläinen, 2002) or surface stiffness (Márquez, Morenilla, Taube, \& Fernández-del-Olmo, 2014) are directly related to $K_{\text {leg }}$ and $K_{\text {vert }}$, so that these factors also influence running economy and performance (Barnes et al., 2014; McMahon, Valiant, \& Frederick, 1987).

It has been previously reported that $\mathrm{K}_{\mathrm{leg}}$ is adjusted at different running velocities in order to accommodate to the landing impact (Farley et al., 1991; Kuitunen et al., 2002; Scholz, Bobbert, van Soest, Clark, \& van Heerden, 2008), leading to an increased efficiency of the elastic energy storage and reutilization during running (Dalleau, Belli, Bourdin, \& Lacour, 1998; Kyröläinen, Belli, \& Komi, 2001). It is also well established that when velocity is increased, the mechanical properties of the spring-mass model need to be adjusted to perform shorter ground contact times (Farley \& González, 1996; Kuitunen et al., 2002). The adjustments in $\mathrm{K}_{\mathrm{vert}}$ and $\mathrm{K}_{\mathrm{leg}}$, may lead to an increase in vertical ground reaction force and/or a decrease in either vertical displacement of the CoM or changes in leg length during the ground contact phase (Arampatzis, Brüggermann, \& Metzler, 1999; Brughelli \& Cronin, 2008; Farley \& González, 1996; Kuitunen et al., 2002).

On the other hand, it is not so clear how $\mathrm{K}_{\mathrm{vert}}$ and $\mathrm{K}_{\text {leg }}$ are modulated during running and hopping when acceleration of the body is changed. It has been recently demonstrated that $K_{\text {leg }}$ remains unchanged during maximal hopping under different loading conditions (i.e.: +10 to $+30 \%$ ) (Kramer, Ritzmann, Gruber, \& Gollhofer, 2012). However, Carretero-Navarro and Márquez (2016) have shown that $\mathrm{K}_{\mathrm{leg}}$ increased during hopping with loads above $+10 \%$ of body mass (BM), but only when the hopping frequency was high $(3.0 \mathrm{~Hz})$. The authors suggested that shorter ground contact times imposed by higher hopping frequencies lead to larger $\mathrm{K}_{\mathrm{leg}}$ values in order to generate sufficiently high momentum to cope with changes in body mass. A recent study also reported increased $\mathrm{K}_{\mathrm{leg}}$ during running when wearing a weighted vest with an additional mass of $10 \%$ of BM (Silder, Besier, \& Delp, 2015). In addition, Sainton, Nicol, Cabri, Barthèlemy-Montfort, and Chavet (2017) suggested that during partial unweigthed running (using an AlterG ${ }^{\circledR}$ treadmill) passive mechanisms together with neuromuscular mechanisms play a major role in adjusting mechanical behaviour of the running pattern, which in turn might lead to a nearly constant $\mathrm{K}_{\text {leg. }}$ Therefore, both passive (i.e.: leg retraction) and active (i.e.: feed-forward control) mechanisms are assumed to interact in order to adapt $K_{\text {leg }}$ during running under different loading/gravity conditions (Kramer et al., 2012; Sainton et al., 2017). These mechanisms might be similar to those during variation of the ground properties and the visual information (Müller, Grimmer, \& Blickhan, 2010; Müller, Häufle, \& Blickhan, 2015; Seyfarth, Geyer, \& Herr, 2003). However, to the best of our knowledge, it has not been tested yet the interaction of different loading and velocity conditions on running kinetics and kinematics. Therefore, the purpose of this study was to investigate the effects of different loading conditions at different running velocities on the spring-mass behaviour. Based on the studies mentioned above, we hypothesized that running mechanics will be altered under different loading and velocity conditions in order to adjust leg and vertical stiffness to maximize neuromuscular efficiency.

\section{Methods}

\section{Participants}

Thirteen recreationally active and healthy males (age: $24 \pm 1.73$ years; BM: $71.63 \pm 10.19 \mathrm{~kg}$; height: 1.74 $\pm 0.06 \mathrm{~m}$ ) participated in this study. All participants signed an informed written consent and all experimental procedures were carried out according to the last review of Declaration of Helsinki and approved by the local ethics committee.

\section{Procedures}

All subjects participated in two separate sessions one week apart. In the first one, they performed an incremental maximal running test on a treadmill to determine their maximal aerobic speed (MAS) (Billat \& Koralsztein, 1996). After a standardized warm-up ( 8 min on a treadmill at $1.94 \mathrm{~m} \cdot \mathrm{s}^{-1}$ ), subjects were required to run on the treadmill (Excite ${ }^{\circledR}$ Run MD, Technogym SpA, Cesena, Italy) at an initial speed of $2.22 \mathrm{~m} \cdot \mathrm{s}^{-1}$ that was progressively increased by $0.28 \mathrm{~m} \cdot \mathrm{s}^{-1}$ every minute until volitional 
exhaustion. The highest velocity reached in the last completed stage was considered as MAS (Billat \& Koralsztein, 1996).

During the second session, after a standardized warm-up (five min running at $2.22 \mathrm{~m} \cdot \mathrm{s}^{-1}$ ) the subjects were instructed to run during $1 \mathrm{~min}$ on a treadmill under different loading $(0 \%,+10 \%$ and $+20 \%$ of BM) and velocity $(60 \%, 80 \%$ and $100 \%$ of MAS) conditions (independent variables). The different loading conditions were set using weighted vests, which allowed adjusting the body mass with an accuracy of $0.1 \mathrm{~kg}$. These nine conditions (3 velocities $\times 3$ loads) were randomized for each participant. The recovery between each trial consisted of 5 min sitting in order to avoid fatigue interactions.

\section{Data analysis}

Spatiotemporal data were recorded during the last $20 \mathrm{~s}$ of each condition using an opto-electrical device (Optogait ${ }^{\circledR}$, Microgate S.r.I., Bolzano, Italy), which allows to record contact time $\left(C_{t}\right)$, flight time $\left(F_{t}\right)$ and step length $\left(S_{L}\right)$ at a frequency of $1000 \mathrm{~Hz}$. The mean values of the $20 \mathrm{~s}$ recordings were considered for the analysis and used to calculate step frequency $\left(S_{F}\right)$ as $S_{F}=1 \cdot\left(C_{t}+F_{t}\right)^{-1}$.

The spring-mass model (Blickhan, 1989; McMahon \& Cheng, 1990) was used to compute the mechanical leg behaviour during the ground contact. For this purpose, the method validated by Morin, Dalleau, Kyröläinen, Jeannin, and Belli (2005) was used to calculate vertical displacement of the CoM $(\Delta y)$, changes in leg length $(\Delta \mathrm{L})$, peak vertical ground reaction force $\left(\mathrm{F}_{\text {peak }}\right)$, vertical stiffness $\left(K_{\text {vert }}\right)$ and leg stiffness $\left(K_{\text {leg }}\right)$ as follows:

$$
\begin{gathered}
\text { Fpeak }=m \cdot g \cdot \frac{\pi}{2} \cdot\left(\frac{F t}{C t}+1\right) ; \text { in } k N \\
\Delta y=\frac{\text { Fpeak } \cdot C t^{2}}{m \cdot \pi^{2}}+g \cdot \frac{C t^{2}}{8} ; \text { in } m \\
\Delta L=L-\sqrt{L^{2}-\left(\frac{v \cdot C t}{2}\right)^{2}}+\Delta y \text {; in } m \\
\text { Kvert }=\frac{\text { Fpeak }}{\Delta y} ; \text { in } k N \cdot m^{-1} \\
\text { Kleg }=\frac{\text { Fpeak }}{\Delta L} ; \text { in } k N \cdot m^{-1}
\end{gathered}
$$

Where $m$ is body mass (in $\mathrm{kg}$ ); $g$ is gravity force (in $\mathrm{N}$ ); $F_{\mathrm{t}}$ is flight time (in s); $C_{t}$ is contact time (in s); $L$ is leg length (in $\mathrm{m}$; great trochanter to ground distance in a standing position); $v$ is running velocity (in $\mathrm{m} \cdot \mathrm{s}^{-1}$ ).

\section{Statistical analysis}

A two-way ANOVA of repeated measures (RMANOVA) was performed with LOAD $(0 \%,+10 \%$ and $20 \%$ of BM) and VELOCITY $(60 \%, 80 \%$ and $100 \%$ of MAS) as factors. Post-hoc analysis was performed using paired $t$ test with Bonferroni correction. None of the data violated the normality assumption necessary to conduct parametric statistical tests. Statistical significance was set at $P \leq .05$ for all analysis. All data were analyzed using SPSS (version 21.00; SPSS Inc, Chicago, IL).

\section{Results}

\section{Treadmill test}

At the incremental running test, participants reached maximal velocities of up to $4.66 \pm 0.09 \mathrm{~m} \cdot \mathrm{s}^{-1}$. Based on this incremental test, the individual velocities to reach $60 \%$ and $80 \%$ of MAS were determined and used in the subsequent session.

\section{Spatiotemporal variables}

Regarding the contact time $\left(C_{t}\right)$, the RM-ANOVA showed a significant effect for VELOCITY $\left(F_{2}, 24\right.$ $\left.=497.21, P<.001, \eta_{p}^{2}=0.976,1-\beta=1\right)$ and LOAD $\left(F_{2}, \quad{ }_{24}=24.913, \quad P<.001, \quad \eta_{p}^{2}=0.675, \quad 1-\beta=1\right)$ without interactions between the two factors. More specifically, a significant decrease in $C_{t}$ occurred when velocity was increased $(P<.001$ for all comparisons). In contrast, the opposite effect (longer $\left.C_{t}\right)$ was found when load was increased $(P<.05$ for all comparisons; Table I).

For the flight time $\left(F_{t}\right)$, the statistical analysis revealed a significant effect for both VELOCITY $\left(F_{2,24}=73.990, P<.001, \eta_{p}^{2}=0.860,1-\beta=0.99\right)$ and $\operatorname{LOAD}\left(F_{2,24}=17.858, P<.001, \eta_{p}^{2}=0.598\right)$. The analysis showed higher $F_{t}$ as velocity increased $(P<.01$ for all comparisons), and a significant reduction when load was increased $(P<.05$ for all comparisons; Table I).

For the step frequency $\left(S_{F}\right)$, the RM-ANOVA showed a significant main effect for VELOCITY $\left(F_{2}, \quad 24=104.229, \quad P<.001, \quad \eta_{p}^{2}=0.897, \quad 1-\beta=1\right)$ and $\operatorname{LOAD}\left(F_{2}, 24=4.359, P=.024, \eta_{p}^{2}=0.266\right.$, $1-\beta=0.70)$. Post hoc comparisons revealed higher step frequency when velocity increased $(P<.001$ for all comparisons; Table I). Similarly, $S_{F}$ was influenced by load but in this case only the highest load condition $(+20 \% \mathrm{BM})$ resulted in significantly increased frequencies compared to the 
Table I. Contact time $\left(C_{T}\right)$, Flight time $\left(F_{T}\right)$, Step length $\left(S_{L}\right)$, Step frequency $\left(S_{F}\right)$ during.

\begin{tabular}{|c|c|c|c|c|c|c|c|c|c|}
\hline \multirow{2}{*}{$\begin{array}{l}\text { Velocity } \\
\text { Load }\end{array}$} & \multicolumn{3}{|c|}{$60 \%$ MAS } & \multicolumn{3}{|c|}{$80 \%$ MAS } & \multicolumn{3}{|c|}{$100 \%$ MAS } \\
\hline & $+0 \% \mathrm{BM}$ & $+10 \% \mathrm{BM}$ & $+20 \% \mathrm{BM}$ & $+0 \% \mathrm{BM}$ & $+10 \% \mathrm{BM}$ & $+20 \% \mathrm{BM}$ & $+0 \% \mathrm{BM}$ & $+10 \% \mathrm{BM}$ & $+20 \% \mathrm{BM}$ \\
\hline$C_{T}(\mathrm{~s})$ & $\begin{array}{r}0.308 \pm \\
0.029\end{array}$ & $\begin{array}{r}0.316^{\mathrm{a}} \pm \\
0.025\end{array}$ & $\begin{array}{c}0.324^{\mathrm{a}, \mathrm{b}} \pm \\
0.030\end{array}$ & $\begin{array}{c}0.251^{1} \pm \\
0.025\end{array}$ & $\begin{array}{c}0.259^{1, \mathrm{a}} \pm \\
0.019\end{array}$ & $\begin{array}{c}0.265^{1, a, b} \pm \\
0.021\end{array}$ & $\begin{array}{c}0.217^{1,2} \pm \\
0.016\end{array}$ & $\begin{array}{c}0.220^{1,2, a} \pm \\
0.013\end{array}$ & $\begin{array}{c}0.227^{1,2, a, b} \pm \\
0.018\end{array}$ \\
\hline$F_{T}(\mathrm{~s})$ & $\begin{array}{r}0.064 \pm \\
0.024\end{array}$ & $\begin{array}{r}0.056^{\mathrm{a}} \pm \\
0.024\end{array}$ & $\begin{array}{c}0.044^{\mathrm{a}, \mathrm{b}} \pm \\
0.028\end{array}$ & $\begin{array}{r}0.103^{1} \pm \\
0.026\end{array}$ & $\begin{array}{c}0.091^{1, \mathrm{a}} \pm \\
0.023\end{array}$ & $\begin{array}{c}0.082^{1, a, b} \mathrm{~b} \\
0.021\end{array}$ & $\begin{array}{c}0.116^{1,2} \pm \\
0.017\end{array}$ & $\begin{array}{c}0.106^{1,2, a} \pm \\
0.014\end{array}$ & $\begin{array}{c}0.097^{1,2, a, b} \pm \\
0.017\end{array}$ \\
\hline$S_{L}(\mathrm{~m})$ & $\begin{array}{c}1.04 \pm \\
0.09\end{array}$ & $\begin{array}{c}1.06 \pm \\
0.09\end{array}$ & $\begin{array}{c}1.03^{\mathrm{a}} \pm \\
0.09\end{array}$ & $\begin{array}{c}1.32^{1} \pm \\
0.10\end{array}$ & $\begin{array}{c}1.30^{1} \pm \\
0.11\end{array}$ & $\begin{array}{c}1.30^{1, \mathrm{a}} \pm \\
0.010\end{array}$ & $\begin{array}{c}1.55^{1,2} \pm \\
0.13\end{array}$ & $\begin{array}{c}1.51^{1,2} \pm \\
0.11\end{array}$ & $\begin{array}{c}1.51^{1,2, a} \pm \\
0.11\end{array}$ \\
\hline$S_{F}\left(\right.$ step $\left.\cdot \mathrm{s}^{-1}\right)$ & $\begin{array}{r}2.69 \pm \\
0.13\end{array}$ & $\begin{array}{r}2.69 \pm \\
0.16\end{array}$ & $\begin{array}{r}2.72^{\mathrm{a}} \pm \\
0.15\end{array}$ & $\begin{array}{c}2.83^{1} \pm \\
0.16\end{array}$ & $\begin{array}{c}2.86^{1} \pm \\
0.16\end{array}$ & $\begin{array}{c}2.89^{1, \mathrm{a}} \pm \\
0.15\end{array}$ & $\begin{array}{c}3.08^{1,2} \pm \\
0.17\end{array}$ & $\begin{array}{c}3.08^{1,2} \pm \\
0.16\end{array}$ & $\begin{array}{c}3.09^{1,2, a} \pm \\
0.17\end{array}$ \\
\hline
\end{tabular}

${ }^{1}$ and ${ }^{2}$ represents significant differences from $60 \%$ MAS and $80 \%$ MAS conditions respectively. ${ }^{a}$ and ${ }^{b}$ represents significant differences from $+0 \% \mathrm{BM}$ and $+10 \% \mathrm{BM}$ loading conditions, respectively. ${ }^{\text {a, }}$, , 1, 2 represent $P<.05$; $^{\text {a, }} \mathbf{b}, 1,2$ (superscript bold) represent $P<.01$.

unloaded condition ( $T=0.054, P=.027$; Table I). Comparable results were found for step length $\left(\mathrm{S}_{\mathrm{L}}\right)$, where RM-ANOVA revealed a significant main effect for VELOCITY $\left(F_{2,24}=825.275, P\right.$ $\left.<.001, \eta_{p}^{2}=0.886,1-\beta=1\right)$ and $\operatorname{LOAD}\left(F_{2,24}=\right.$ 4.016, $\left.P=.031, \eta_{p}^{2}=0.897,1-\beta=0.66\right)$ without interactions between the two factors. Post-hoc tests demonstrated greater step length as velocity is increased $(P<.001$ for all comparisons; Table I). However, $S_{\mathrm{L}}$ significantly decreased during the heaviest loading condition $(+20 \% \mathrm{BM})$ compared to the unloaded one $(+0 \% \mathrm{BM})(T=-2.4, P$ $=.023$; Table I).

\section{Spring mass model behaviour}

Spring mass model behaviour during running under different loading and velocity conditions is displayed in Figure 1. The current results show a significant main effect of VELOCITY $\left(F_{2,24}=125.946, P\right.$ $\left.<.001, \eta_{p}^{2}=0.913,1-\beta=1\right)$ and LOAD $\left(F_{2,24}=\right.$ 51.022, $\left.P<.001, \eta_{p}^{2}=0.810,1-\beta=1\right)$ for the peak vertical ground reaction force. Post hoc analysis revealed a significant increase in $F_{\text {peak }}$ as velocity and/or load increased $(P<.01$ for all comparisons; Figure 1(e)). Regarding vertical displacement of the CoM ( $\Delta y)$, RM-ANOVA showed a significant effect of VELOCITY $\left(F_{2,24}=235.204, P<.001, \eta_{p}^{2}=\right.$ $0.951,1-\beta=1)$ and $\operatorname{LOAD}\left(F_{2,}, 24=22.729, P\right.$ $\left.<.001, \eta_{p}^{2}=0.654,1-\beta=1\right)$. The $\Delta \mathrm{y}$ decreased as velocity increased $(P<.001$ for all comparisons; Figure $1(\mathrm{c}))$ but increased with greater loads $(P<.05$ for all comparisons; Figure 1(c)). For the changes in leg length $(\Delta \mathrm{L}), \mathrm{RM}$-ANOVA showed a main effect of VELOCITY $\left(F_{2}, 24=12.214, P=.001, \eta_{p}^{2}=\right.$ $0.504,1-\beta=0.99)$ and $\operatorname{LOAD}\left(F_{2,24}=25.448, P\right.$ $\left.<.001, \quad \eta_{p}^{2}=0.680, \quad 1-\beta=1\right)$. When velocity increased, $\Delta \mathrm{L}$ was reduced $(P<.05$ for all comparisons; Figure 1(d)). However, when load was increased, $\Delta \mathrm{L}$ values also increased $(P<.05$ for all comparisons; Figure 1(d)). Regarding stiffness parameters, RM-ANOVA showed a significant effect of VELOCITY on $\mathrm{K}_{\text {vert }}\left(F_{2,24}=319.497, P<.001\right.$, $\eta_{p}^{2}=0.975,1-\beta=1$; Figure $\left.1(\mathrm{a})\right)$ and $\mathrm{K}_{\mathrm{leg}}\left(F_{2,24}=\right.$ 52.577 $P<.001, \eta_{p}^{2}=0.901,1-\beta=1$; Figure $1(\mathrm{~b})$ ). In contrast, $\mathrm{K}_{\mathrm{vert}}$ and $\mathrm{K}_{\text {leg }}$ remained nearly constant when load was changed (no significant effect of the different loading conditions on $\mathrm{K}_{\mathrm{vert}}$ and $\mathrm{K}_{\mathrm{leg}}$ ).

\section{Discussion}

The main results highlighted how $\mathrm{K}_{\mathrm{leg}}$ and $\mathrm{K}_{\mathrm{vert}}$ remained constant at different submaximal running velocities despite changes in loading. This was achieved by changing running kinematics and kinetics as is discussed in the following sections.

\section{Effect of loading on $K_{\text {leg }}$ and $K_{\text {vert }}$}

The results obtained in the current study suggest that additional loading did not affect $\mathrm{K}_{\text {leg }}$ or $\mathrm{K}_{\mathrm{vert}}$ levels, or in other words, stiffness properties could be maintained despite changes in loading. This is in line with previous studies investigating hopping (Kramer et al., 2012; Kuitunen, Ogiso, \& Komi, 2011). In those studies, $\mathrm{K}_{\mathrm{leg}}$ remained unaltered despite the increase in $\mathrm{F}_{\text {peak }}$ with additional loading. As a consequence, $\Delta \mathrm{y}$ and $\Delta \mathrm{L}$ increased leading to constant stiffness levels (Kramer et al., 2012). It has been shown that $C_{t}$ significantly increased when loading was higher than $+5 \%$ of BM (Macadam, Cronin, \& Simperingham, 2017). This increase of $C_{t}$ was directly related to higher vertical excursions of the CoM and larger deformations of the leg during the ground contact phase. In this line, Kramer et al. (2012) proposed that these adjustments are explained by the increased kinetic energy, similar to a spring which is compressed more and for a longer time when more 
A)


B)

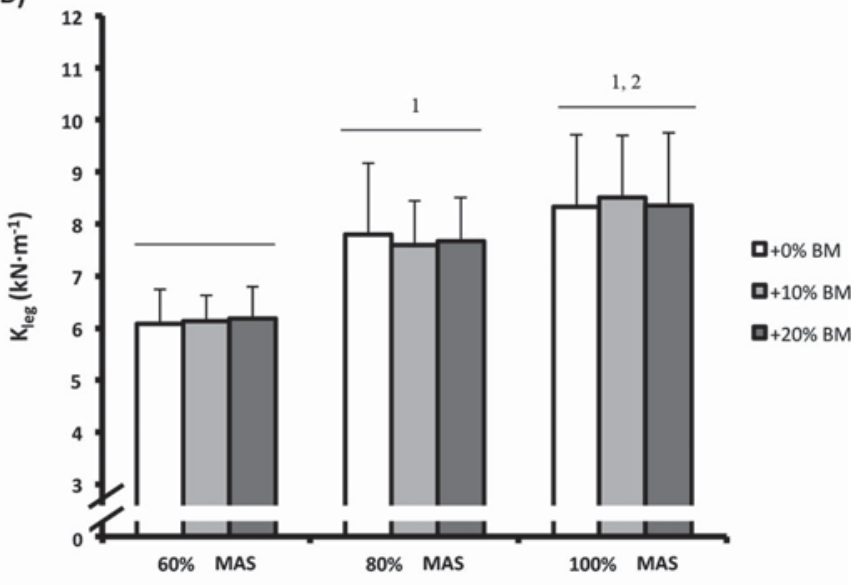

D)



Figure 1. The effects of both velocity and load on running kinematics are represented for $\mathrm{K}_{\text {vert }}(\mathrm{A}), \mathrm{K}_{\mathrm{leg}}(\mathrm{B}), \Delta \mathrm{y}(\mathrm{C}), \Delta \mathrm{L}(\mathrm{D}), \mathrm{F}_{\mathrm{peak}}(\mathrm{E})$. White bars represent bodyweight condition (+0\% BM); grey bars represent $+10 \% \mathrm{BM}$ condition; and dark-grey bars represent $+20 \% \mathrm{BM}$. ${ }^{1}$ represents significant differences from $60 \%$ MAS; ${ }^{2}$ means significantly different from $80 \%$ MAS. ${ }^{a}$ represents significant differences from $+0 \%$

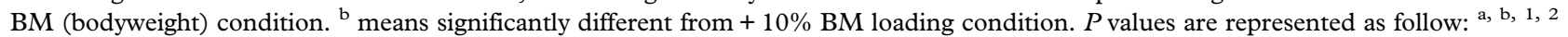
means $P<.05 ;{ }^{\text {a, }} \mathbf{b}, \mathbf{1}, \mathbf{2}$ (superscript bold) means $P<.01$. Data are represented as the mean \pm typical error.

energy is supplied due to an increase in acceleration (or loading).

Kuitunen et al. (2011) suggested that the objective of the neuromuscular system seems to maintain optimal
$\mathrm{K}_{\text {leg }}$ levels independently of the resultant $\mathrm{F}_{\text {peak }}$. These neural adjustments incorporate higher pre-activation (Kuitunen et al., 2011) and higher EMG activity at the time of medium- and long- latency responses 
(Kramer et al., 2012) of the ankle extensors. According to Kramer et al. (2012), the observation that leg stiffness remained unaltered underlines the ability of the neuromuscular system to maintain particular recoil properties in spite of the different loading conditions. This is in line with previous studies supporting the hypothesis that the neuromuscular system adjusts leg stiffness to maintain an efficient spring-mass behaviour regardless of external constraints (Ferris et al., 1998; Márquez et al., 2014). In addition, a recent study that measured neuromechanical adaptations in response to partial unweighted running suggested that passive mechanisms (i.e.: leg retraction) might play a role, together with active mechanisms (i.e.: feed-forward control), when changes in flight time and step frequency occurs, resulting in a nearly constant $K_{\text {leg }}$ (Sainton et al., 2017).

The current results are, however, in contrast to findings obtained by Silder et al. (2015) showing increases in $\mathrm{K}_{\mathrm{leg}}$ during running with loads heavier than $+10 \%$ of BM. Contrary to the present study and previous approaches investigating hopping (Kramer et al., 2012; Kuitunen et al., 2011), the authors reported lowered $\Delta \mathrm{L}$ values when load increased above $10 \%$ of BM despite significant increases in $C_{t}$ and peak hip, knee and ankle flexion at the time of ground contact. The authors suggested that the subjects adopted a running pattern similar to that described as "Groucho running" when carrying loads, characterized by an increase in lower extremity joint flexion angles, longer contact times, and lower peak vertical reaction forces (McMahon et al., 1987). These contrary results could be due to the different methodology used to compute kinetic and kinematic data. The indirect assessment of leg stiffness in the current study may be seen as a limitation. However, this methodology has been demonstrated to be valid and reliable during running (Coleman, Cannavan, Horne, \& Blazevich, 2012; Morin et al., 2005; Pappas, Paradisis, Tsolakis, Smirniotou, \& Morin, 2014). Thus, other factors such as the constitution of the athletes, weight distribution within the vest, identical running velocity with and without load and/or other factors may have led to the observation of a "crouched position with increased leg stiffness" in the study of Silder et al. (2015). In any case, further studies are needed to explore these apparent discrepancies. One issue might indeed be the influence of the running velocity as is illustrated in the next section.

\section{Effect of velocity and loading interactions on $K_{\text {leg }}$ and $K_{\text {vert }}$}

The relationship between spatiotemporal and kinetic variables with stiffness parameters has been reported in earlier studies. Farley and González (1996) showed that with higher $S_{F}$ at the same speed $\left(2.5 \mathrm{~m} \cdot \mathrm{s}^{-1}\right)$ the leg becomes more rigid, consequently $\mathrm{K}_{\text {leg }}$ and $\mathrm{K}_{\mathrm{vert}}$ increase while $C_{t}, \Delta \mathrm{y}$, and $\Delta \mathrm{L}$ decrease. Analyzing stiffness adjustments at different velocities, Kuitunen et al. (2002) reported shorter $C_{t}$ when individual ankle joint stiffness was higher. However, the ankle joint stiffness did not further increase when the velocity exceeded $70 \%$ of the maximum sprinting speed. In contrast, knee stiffness and vertical stiffness reached their maximum at the maximal sprinting velocity. This has also been suggested by Arampatzis et al. (1999), who have proposed that knee stiffness plays an important role to adapt leg spring stiffness when running velocity is increased. In this sense, our results are in accordance with the abovementioned observations as running mechanics is completely adapted to the new constraints imposed by higher velocities. Moreover, in the present study the stiffness adjustments due to changes in running velocity are consistent with previous observations showing higher $\mathrm{K}_{\text {leg }}$ and $\mathrm{K}_{\mathrm{vert}}$ levels when velocity increases (higher $S_{F}$, longer $S_{L}$ and shorter $C_{t}$ ) (Arampatzis et al., 1999; Kuitunen et al., 2002; Morin et al., 2005).

However, when analyzing velocity and loading interactions, Carretero-Navarro and Márquez (2016) reported a significant increase of $\mathrm{K}_{\mathrm{leg}}$ when subjects performed high frequency hopping $(3.0 \mathrm{~Hz})$ with additional loads above $10 \%$ of BM. It may be assumed that at this high frequency (i.e.: higher velocities), the system tends to increase its stiffness to compensate the effect of an increase in force application, and as a consequence, the duration of $C_{t}$ and the displacement of the CoM are changed. However, in the present study we used submaximal velocities and during these velocities, $K_{v e r t}$ and $K_{\text {leg }}$ were maintained constant despite the observed higher loading rates (i.e.: higher $F_{\text {peak }}$ ). In this regard, although some studies investigated kinetic and spatiotemporal adjustments during sprinting with weighted vests (for more detailed information see Macadam et al., 2017), there are no studies investigating $\mathrm{K}_{\mathrm{leg}}$ and $\mathrm{K}_{\mathrm{vert}}$ under different loading conditions during maximal velocity actions (i.e.: sprint). Therefore, future studies should analyze whether different loading conditions could affect the spring-mass behaviour during running at velocities above MAS.

\section{Practical considerations}

From a practical point of view, a previous study (Barnes, Hopkins, Mcguigan, \& Kilding, 2015) demonstrated that wearing a weighted vest loaded 
with $20 \%$ of $\mathrm{BM}$ during a submaximal running warm-up resulted - after a 10 min recovery period in a very-large enhancement of peak running speed $(2.9 \%)$, a moderate increase in leg stiffness $(20.4 \%)$ and a large improvement in running economy $(6.0 \%)$, together with small to moderate reductions in cardiorespiratory measures. Furthermore, this study also showed that changes in leg stiffness could explain all the improvements in performance and economy. Therefore, it seems that stiffness is a very important factor related to endurance performance (Hobara et al., 2010). This is also evident from the results obtained by Hayes and Caplan (2014), which revealed that $\mathrm{K}_{\text {leg }}$ is reduced during a run to exhaustion at MAS. In addition, authors also found a strong relationship between $\mathrm{K}_{\text {leg }}$ and the time to exhaustion and the distance covered during the test, indicating that $\mathrm{K}_{\mathrm{leg}}$ provided a better prediction of performance than metabolic predictors. Furthermore, these modifications in mechanical and spatiotemporal parameters are well explained by changes in lower limb muscular activity, as shown by Rabita, Couturier, Dorel, Hausswirth, and Le Meur (2013). These authors demonstrated that plantarflexors were more affected by the run to exhaustion than knee extensors, which did not present changes in their activity. However, biarticular rectus femoris and biceps femoris seem to play an important role in order to maintain the preset velocity at the latter stage of the run (Rabita et al., 2013). Given that, our result may provide a better understanding of the acute effects of different loading conditions on the spring-mass behaviour during running at different velocities, and therefore, it could help coaches to make decisions regarding the use of weighted vests during a training session.

On the other hand, although lower extremity stiffness has been shown to be important for optimal running performance (Barnes et al., 2015; Hayes \& Caplan, 2014; Hobara et al., 2010), there is evidence to suggest that too much stiffness may result in a higher incidence of injury (Butler, Crowell, \& Davis, 2003). In this regard, our results revealed a linear increase in $\mathrm{F}_{\text {peak }}$ proportional to the load imposed by the weighted vests. This greater $F_{\text {peak }}$ may be potentially related with a higher injury risk of the lower extremity (Henning \& Lafortune, 1991). However, our runners also displayed larger $\Delta \mathrm{y}$ and $\Delta \mathrm{L}$ that led to maintain similar stiffness levels in spite of the extra load imposed during running under the different loading conditions $(0-20 \% \mathrm{BM})$. This could be interpreted as a mechanism to compensate for a potentially increased loading rate and shock to the lower extremity (Henning \& Lafortune, 1991), which in turn would lead to an increased risk of bony injuries and stress fractures (Grimston, Engsberg, Kloiber, \&
Hanley, 1991). Therefore, future studies may also address the effects of new training protocols using different loading and velocity conditions in order to develop the optimal training stimulus to enhance athletic performance and reduce injury rates.

\section{Conclusion}

In conclusion, $\mathrm{K}_{\mathrm{leg}}$ and $\mathrm{K}_{\mathrm{vert}}$ remained constant when wearing weighted vests loaded with $10-20 \%$ of the $\mathrm{BM}$ during running at different submaximal velocities. At the same time, alterations of the running kinematics were observed such as longer contact times, reduced flight times, stride frequencies and step lengths, as well as an increase of the CoM dynamics. Based on these results it is assumed that runners maintain a certain stiffness level for each velocity despite different loading conditions. As a consequence, $F_{\text {peak }}$ increases and this probably causes spatiotemporal adjustments in the movement kinematics. Based on previous studies, it has been suggested that these adjustments in the mechanics of running under different loading conditions may be due to the interactions of passive (i.e.: leg retraction) and active (i.e.: feed-forward) mechanism. However, further research is needed in order to determine the underlying mechanisms involved in stiffness regulation while running with weighted vests. In contrast, stiffness was adjusted according to the running velocity, thus higher $K_{\text {leg }}$ and $K_{v e r t}$ were evident at faster velocities. Altogether, these results should be taken into consideration when planning a training session oriented to improve springmass behaviour and thus, performance.

\section{Disclosure statement}

No potential conflict of interest was reported by the authors.

\section{ORCID}

Gonzalo Márquez (D) http://orcid.org/0000-00022305-5229

\section{References}

Abe, D., Fukuoka, Y., Muraki, S., Yasukouchi, A., Sakaguchi, Y., \& Niihata, S. (2011). Effects of load and gradient on energy cost of running. Fournal of Physiological Anthropology, 30(4), 153-160.

Arampatzis, A., Brüggermann, G. F., \& Metzler, V. (1999). The effect of speed on leg stiffness and joint kinetics in human running. Fournal of Biomechanics, 32, 1349-1353.

Barnes, K. R., Hopkins, W. G., Mcguigan, M. R., \& Kilding, A. E. (2015). Warm-up with a weighted vest improves running 
performance via leg stiffness and running economy. Fournal of Science and Medicine in Sport, 18(1), 103-108.

Barnes, K. R., McGuigan, M. R., \& Kilding, A. E. (2014). Lowerbody determinants of running economy in male and female distance runners. Fournal of Strength and Conditioning Research, 28 (5), 1289-1297.

Billat, L. V., \& Koralsztein, J. P. (1996). Significance of the velocity at VO2max and time to exhaustion at this velocity. Sports Medicine, 22(2), 90-108.

Blickhan, R. (1989). The spring-mass model for running and hopping. Fournal of Biomechanics, 22(11), 1217-1227.

Brughelli, M., \& Cronin, J. (2008). Influence of running velocity on vertical, leg and joint stiffness: Modelling and recommendations for future research. Sports Medicine, 38(8), 647-657.

Butler, R. J., Crowell, H. P., \& Davis, I. M. (2003). Lower extremity stiffness: Implications for performance and injury. Clinical Biomechanics, 18(6), 511-517.

Carretero-Navarro, G., \& Márquez, G. (2016). Effect of different loading conditions on leg stiffness during hopping at different frequencies. Science and Sports, 31(2), e27-e31.

Coleman, D. R., Cannavan, D., Horne, S., \& Blazevich, A. J. (2012). Leg stiffness in human running: Comparison of estimates derived from previously published models to direct kinematic-kinetic measures. Fournal of Biomechanics, 45(11), 1987-1991.

Dalleau, G., Belli, A., Bourdin, M., \& Lacour, J. R. (1998). The spring-mass model and the energy cost of treadmill running. European Fournal of Applied Physiology and Occupational Physiology, 77(3), 257-263.

Farley, C. T., Blickhan, R., Saito, J., \& Taylor, C. R. (1991). Hopping frequency in humans: A test of how springs set stride frequency in bouncing gaits. Fournal of Applied Physiology, 71(6), 2127-2132.

Farley, C. T., \& González, O. (1996). Leg stiffness and stride frequency in human running. Fournal of Biomechanics, 29(2), 181-186.

Ferris, D. P., Louie, M., \& Farley, C. T. (1998). Running in the real world: Adjusting leg stiffness for different surfaces. Proceedings of the Royal Society B: Biological Sciences, 265 (1400), 989-994.

Grimston, S. K., Engsberg, J. R., Kloiber, R., \& Hanley, D. A. (1991). Bone mass, external loads, and stress fracture in female runners. International fournal of Sport Biomechanics, 7 (3), 293-302.

Hayes, P. R., \& Caplan, N. (2014). Leg stiffness decreases during a run to exhaustion at the speed at VO2max. European fournal of Sport Science, 14(6), 556-562.

Henning, E. M., \& Lafortune, M. A. (1991). Relationships between ground reaction force and tibial bone acceleration parameters. International fournal of Sport Biomechanics, 7(3), 303-309.

Hobara, H., Kimura, K., Omuro, K., Gomi, K., Muraoka, T., Sakamoto, M., \& Kanosue, K. (2010). Differences in lower extremity stiffness between endurance-trained athletes and untrained subjects. Fournal of Science and Medicine in Sport, 13 (1), 106-111.

Kramer, A., Ritzmann, R., Gruber, M., \& Gollhofer, A. (2012). Leg stiffness can be maintained during reactive hopping despite modified acceleration conditions. Fournal of Biomechanics, 45(10), 1816-1822.
Kuitunen, S., Komi, P., \& Kyröläinen, H. (2002). Knee and ankle joint stiffness in sprint running. Medicine $\mathcal{E}$ Science in Sports and Exercise, 34(1), 166-173.

Kuitunen, S., Ogiso, K., \& Komi, P. V. (2011). Leg and joint stiffness in human hopping. Scandinavian fournal of Medicine and Science in Sports, 21(6), e159-e167.

Kyröläinen, H., Belli, A., \& Komi, P. V. (2001). Biomechanical factors affecting running economy. Medicine and Science in Sports and Exercise, 33(8), 1330-1337. doi:10.1097/00005768200108000-00014

Macadam, P., Cronin, J. B., \& Simperingham, K. D. (2017). The effects of wearable resistance training on metabolic, kinematic and kinetic variables during walking, running, sprint running and jumping: A systematic review. Sports Medicine, 47(5), 887-906.

Márquez, G., Morenilla, L., Taube, W., \& Fernández-del-Olmo, M. (2014). Effect of surface stiffness on the neural control of stretchshortening cycle movements. Acta Physiologica, 212(3), 214-225.

McMahon, T. A., \& Cheng, G. C. (1990). The mechanics of running: How does stiffness couple with speed? fournal of Biomechanics, 23(Suppl. 1), 65-78.

McMahon, T. A., Valiant, G., \& Frederick, E. C. (1987). Groucho running. Fournal of Applied Physiology, 62(6), 2326-2337.

Morin, J. B., Dalleau, G., Kyröläinen, H., Jeannin, T., \& Belli, A. (2005). A simple method for measuring stiffness during running. Fournal of Applied Biomechanics, 21(2), 167-180.

Müller, R., Grimmer, S., \& Blickhan, R. (2010). Running on uneven ground: Leg adjustments by muscle pre-activation control. Human Movement Science, 29, 299-310.

Müller, R., Häufle, D. F. B., \& Blickhan, R. (2015). Preparing the leg for ground contact in running: The contribution of feedforward and visual feedback. Fournal of Experimental Biology, 218, 451-457.

Pappas, P., Paradisis, G., Tsolakis, C., Smirniotou, A., \& Morin, J. B. (2014). Reliabilities of leg and vertical stiffness during treadmill running. Sports Biomechanics, 13(4), 391-399.

Rabita, G., Couturier, A., Dorel, S., Hausswirth, C., \& Le Meur, Y. (2013). Changes in spring-mass behavior and muscle activity during an exhaustive run at $\dot{\mathrm{VO} 2 m a x . ~ F o u r n a l ~ o f ~ B i o m e c h a n i c s, ~}$ 46(12), 2011-2017.

Sainton, P., Nicol, C., Cabri, J., Barthèlemy-Montfort, J., \& Chavet, P. (2017). Correction: Kinetics and muscle activity patterns during unweighting and reloading transition phases in running. PLoS ONE, 12(4), e0176508.

Saunders, P. U., Pyne, D. B., Telford, R. D., \& Hawley, J. A. (2004). Factors affecting running economy in trained distance runners. Sports Medicine, 34(7), 465-485.

Scholz, M. N., Bobbert, M. F., van Soest, A. J., Clark, J. R., \& van Heerden, J. (2008). Running biomechanics: Shorter heels, better economy. Fournal of Experimental Biology, 211, 3266-3271.

Seyfarth, A., Geyer, H., \& Herr, H. (2003). Swing-leg retraction: A simple control model for stable running. Fournal of Experimental Biology, 206, 2547-2555.

Silder, A., Besier, T., \& Delp, S. L. (2015). Running with a load increases leg stiffness. Fournal of Biomechanics, 48(6), 1003-1008.

Williams, K. R., \& Cavanagh, P. R. (1987). Relationship between distance running mechanics, running economy, and performance. Fournal of Applied Physiology, 63(3), 1236-1245. 